\title{
How an ordeal becomes the norm: A qualitative exploration of experiences of selfcannulation in male home haemodialysis patients.
}

DOI:

10.1111/bjhp.12303

\section{Document Version}

Accepted author manuscript

Link to publication record in Manchester Research Explorer

\section{Citation for published version (APA):}

Moore, C., Majeed-Ariss, R., Jayanti, A., Mitra, S., Skevington, S., \& Wearden, A. (2018). How an ordeal becomes the norm: A qualitative exploration of experiences of selfcannulation in male home haemodialysis patients. British Journal of Health Psychology. https://doi.org/10.1111/bjhp.12303

\section{Published in:}

British Journal of Health Psychology

\section{Citing this paper}

Please note that where the full-text provided on Manchester Research Explorer is the Author Accepted Manuscript or Proof version this may differ from the final Published version. If citing, it is advised that you check and use the publisher's definitive version.

\section{General rights}

Copyright and moral rights for the publications made accessible in the Research Explorer are retained by the authors and/or other copyright owners and it is a condition of accessing publications that users recognise and abide by the legal requirements associated with these rights.

\section{Takedown policy}

If you believe that this document breaches copyright please refer to the University of Manchester's Takedown Procedures [http://man.ac.uk/04Y6Bo] or contact uml.scholarlycommunications@manchester.ac.uk providing relevant details, so we can investigate your claim.

\section{OPEN ACCESS}


Running head: Male HHD patients' experiences of self-cannulation

How an ordeal becomes the norm: A qualitative exploration of experiences of selfcannulation in male home haemodialysis patients.

Currie Moore ${ }^{1,2}$, Rabiya Majeed-Ariss ${ }^{3}$, Anuradha Jayanti ${ }^{3}$, Sandip Mitra ${ }^{2,3,4}$, Suzanne Skevington ${ }^{1,2}$ and Alison Wearden ${ }^{1,2}$

${ }^{1}$ University of Manchester, School of Health Sciences

${ }^{2}$ Manchester Academic Health Science Centre

${ }^{3}$ Manchester University NHS Foundation Trust

${ }^{4}$ NIHR Devices for Dignity, Health Technology Cooperative

${ }^{*}$ Requests for reprints should be addressed to Currie Moore, Coupland 1 Building, University of Manchester, School of Health Sciences and Manchester Centre for Health Psychology, Oxford Road, Manchester M13 9PL, UK (e-mail:

currie.moore@postgrad.manchester.ac.uk)

\section{Acknowledgements}

The research team wishes to thank the participants in this study for their willingness to share their experiences with us.

\section{Funding}

Funding for this study was provided by the following: Currie Moore - UK Medical Research Council Doctoral Training Partnership PhD Studentship; Rabiya Majeed-Ariss - CLARHC Fellowship; Anuradha Jayanti - Baxter International Clinical Evidence Council Grant.

None of these funders played any role in the preparation of this paper. 


\begin{abstract}
Objectives: Despite home haemodialysis (HHD) being associated with significant health and psychosocial benefits, it remains an under-utilised dialysis modality for people with chronic kidney disease. Self-cannulation, where patients insert their own needles for dialysis, is a key component of HHD. Recent research suggests that the prospect of selfcannulation is a barrier for patients, but there is little research which examines why this is the case. The aim of this study was to explore male HHD patients' experiences and attitudes towards self-cannulation.
\end{abstract}

Design: Qualitative methods were adopted to gather in-depth views from experienced HHD patients from a UK renal centre.

Methods: Semi-structured interviews were conducted with 8 male HHD patients (HHD duration: $12-55$ months). During the interview, the researcher elicited participants' lived experience of self-cannulation. Topics included the decision to self-cannulate and the impact of self-cannulation on the patient. The data collected were analysed using interpretative phenomenological analysis.

Results: The findings from this study elucidate the process of how self-cannulation changed from an ordeal to the norm in these participants' lives. The central theme from these interviews is that "becoming a person who self-cannulates is a process". Three super-ordinate themes were discussed that relate to this central theme: "gaining control", "building confidence", and "becoming the norm".

Conclusions: The findings from this study suggest that some patients' initial fears of selfcannulation can be overcome. These findings offer healthcare professionals and patients alike a greater understanding of how patients who self-cannulate conceptualise it and its role in their mental and physical health. 
Established renal failure (ERF) is the last stage of chronic kidney disease (CKD) where the kidneys are no longer able to clear toxins from the blood (National Kidney Foundation, 2002). People with ERF therefore rely on renal replacement therapies (RRT), namely kidney transplant, haemodialysis or peritoneal dialysis. Approximately $41 \%$ ERF patients in the UK undergo a form of haemodialysis (MacNeill, Casula, Shaw, \& Castledine, 2016).

In haemodialysis (HD), the individual's blood is circulated through a machine which filters out the toxins and excess fluid via vascular access points. Haemodialysis treatment may be administered in hospitals, in satellite dialysis units, or at home (HHD). HHD patients report better survival rates and quality of life, lower blood pressure and phosphate levels, and reduced reliance on medication compared to those on other forms of dialysis (Mitra \& Jayanti, 2014; Mowatt, Vale, \& MacLeod, 2004; Tennankore, Chan, \& Curran, 2012), and HHD has been shown to be cost-effective (Komenda, Gavaghan, Garfield, Poret, \& Sood, 2012). HHD patients have reported an increased sense of well-being (Wise, Schatell, Klicko, Burdan, \& Showers, 2010) with greater control, freedom and flexibility (Cases, Dempster, Davies, \& Gamble, 2011; Courts, 2000; Lee, Gudex, Povlsen, Bonnevie, \& Nielsen, 2008; Vestman, Hasselroth, \& Berglund, 2014). HHD patients can adapt their treatment to suit themselves (Courts, 2000; Lee et al., 2008; Namiki, Rowe, \& Cooke, 2010; Rygh, Arild, Johnsen, \& Rumpsfeld, 2012) and become active managers of their health (Cases et al., 2011; Curtin, Mapes, Petillo, \& Oberley, 2002; Majeed-Ariss, Jayanti, Schulz, Wearden, \& Mitra, 2016; Rygh et al., 2012). However, despite the clear benefits of HHD, it remains an under-utilised mode of treatment in the UK (MacNeill et al., 2016). 
Studies which have sought to explore patient decision-making have found treatment specific issues (e.g., duration of treatments, dislike of blood or needles) deter patients from choosing HHD. Several studies (Cafazzo, Leonard, Easty, Rossos, \& Chan, 2010; Morton, Tong, Webster, Snelling, \& Howard, 2011; Morton, Tong, Howard, Snelling, \& Webster, 2010; Pipkin et al., 2010; Tennankore et al., 2012; Walker et al., 2015; Wong et al., 2009) have indicated that fear at the prospect of self-cannulation may act as a barrier to HHD, but have failed to explore how this fear may be overcome.

Self-cannulation involves independently inserting and removing dialysis needles using a specially created arteriovenous link called a fistula. Before patients start HHD, renal care teams provide training and support on using the fistula; in the UK, this training is delivered in the renal unit alongside the patients' regular dialysis sessions or during specific training programmes.

To date only one quantitative study has examined patients' perceptions of selfcannulation. Jayanti et al. (2015) surveyed UK patients in pre-dialysis, Hospital HD and HHD about their attitudes towards and concerns about self-cannulation. Among predialysis patients, $62 \%$ believed they could self-cannulate on their own or with help, but once started on hospital dialysis, $53 \%$ of patients did not feel that they would be capable of self-cannulation (Jayanti et al., 2015). Concerns related to several aspects of selfcannulation, for example, infections, catastrophic bleeding, pain, and watching the needle go in (Jayanti et al., 2015).The authors suggested that the optimal time to approach patients about self-cannulation is during pre-dialysis and that some patient concerns may be overcome with appropriate interventions.

Glidewell et al. (2013) interviewed dialysis patients taking part in a UK National Health Service (NHS) based shared-care initiative which promoted self-cannulation. 
Some patients had overcome blood or needle phobias stating that self-cannulation was easy and a way of protecting the health of their fistula, while others lacked confidence, noting that even nurses experienced problems with cannulation. In a study on patients' views of vascular access, some patients regarded being able to self-cannulate as important in developing confidence and knowledge of their access, while for others, fears and pain related to needles prevented them from doing HHD (Taylor et al., 2016). Taken together, these studies highlight the diverse and contrasting views that patients have of needles and self-cannulation.

While self-cannulation is essential for HHD, the evidence suggests there may be psychological barriers to its successful uptake. Research which identifies how successful self-cannulators experience HHD may provide insights into how these psychological barriers have been overcome. In the UK and globally, approximately $70 \%$ of patients who utilise HHD are male (Wilkie, 2011), yet this group has rarely been studied. The aims of this study were to explore the experiences and perspectives on self-cannulation of male HHD patients' who were being treated within the context of the UK NHS, and to highlight ways in which barriers to self-cannulation were overcome.

\section{METHOD}

This study received ethical approval from a UK NHS Research Ethics Committee No. 12/NW/0170).

\section{Study Design}

The present study was part of a larger mixed-methods project, BASIC-HHD, which aimed to explore decision-making about dialysis and perceived barriers to HHD. Given the limited research to date on patient experiences with self-cannulation, a qualitative methodology was selected to explore this topic in-depth. This study was 
conducted with an all male sample both to give this group of patients a voice and to facilitate comparisons between patient experiences during analysis.

\section{Data Collection}

Semi-structured interviews were conducted in order to provide consistency across the interviews while facilitating exploration of the participants' experiences, attitudes and perspectives towards self-cannulation. A topic guide was developed on the basis of clinical experience and pertinent questions arising from the literature. It included questions about patients' decision-making, their experiences with HHD and selfcannulation (see Table 1), which could be supplemented with probe questions. In order to allow patients to tell their stories according to their own perceptions and priorities, the order of questions in the topic guide could be varied, and interesting issues followed up as they arose. Individual interviews were conducted by the first author either at participants' homes or in hospital, whichever was more convenient to the participant. Interviews were interactive and conversational in tone, and the topics were discussed indepth, ranging from 84 minutes to 165 minutes in duration. All interviews were digitally audio-recorded and transcribed verbatim by a professional transcription provider. The first author read the transcripts while listening to the audio-recordings to verify their accuracy, and any identifiable data was removed at this time. Pseudonyms were given to all participants to protect their identity. All portions of the interviews in which the participant referred to self-cannulation were extracted to be analysed separately, noting the location and duration of the extracted passages. Self-cannulation was discussed for an average of 34 minutes per interview.

\section{[Insert Table 1]}




\section{Participants}

8 male patients on HHD took part (see Table 2). The inclusion criteria were: a) at least 18 years old, b) on HHD for 6 months or more, c) a participant in the quantitative arm of the main study, and d) fluent speakers of English. Patients with mental or physical health conditions which impaired their ability to consent or to participate were not invited. Participants for this sample were purposively sampled to reflect a variety of experiences and key demographic variables (i.e., age, duration on HHD, ethnicity). The principal investigator of the overall study identified 8 patients who met the inclusion criteria for this study. All 8 agreed to take part in the interview and gave written informed consent.

\section{[Insert Table 2]}

\section{Data Analysis}

Interpretative phenomenological analysis (IPA, Smith, Flowers, \& Larkin, 2009), a form of analysis widely used in health research (Brocki \& Wearden, 2006) was used to explore the lived experiences of HHD patients with self-cannulation. IPA is especially suited to research which seeks to understand the complex way people make sense of particular experiences (Smith et al., 2009).

Analysis, conducted primarily by the first author, consisted firstly of familiarisation with the data which was achieved through multiple readings of the transcripts. Next, initial notes were made in the left-hand margins to track emerging ideas, vocabulary usage, contradictions and reiterations. Following this, the right-hand margin was used to create emerging themes which were drawn from the initial notes and corresponding quotations. Next, all emerging themes were collated and then clustered into groups according to their meaning. Clusters of themes were grouped into working super- 
ordinate themes, each supported with sub-themes and key quotations from transcript. These were collated into a document and reviewed and discussed by the research team. In accordance with the idiographic nature of IPA (Smith et al., 2009), each participant's data was analysed up to this stage before the researcher proceeded to the next participant. After all participants' data had been analysed, the researcher reviewed the working super-ordinate themes and sub-themes across the sample and formulated a thematic model of the dataset. The thematic model of the data was presented to the research team and refinements were made which captured their interpretations.

To verify the validity of the results, the thematic model was presented to a participant in the study. Member-checking ensures that the meaning and experiences were correctly understood by the researcher (Tong, Sainsbury, \& Craig, 2007). The participant agreed that the analysis was a reflection of participants' experiences, attitudes and perspectives.

\section{Results}

The thematic model which emerged from this data is presented in Table 3. A central theme, Becoming a person who self-cannulates is a process, is supported by three super-ordinate themes: gaining control, building confidence, and becoming the norm. This central theme and the super-ordinate themes are discussed in turn.

\section{[Insert Table 3]}

\section{Becoming a person who self-cannulates is a process}

The participants in this study described coming to terms with self-cannulation as a process: 
They've got to go through this process of either being frightened of needles, overcoming it, learning how to do it - and as I say that's going to be a 6 month process. Eli

I feel that it's just a training process. If you take it as a training process it's not as difficult you know, it's just living your life another way. And once you get past that, you know, that initial shock and you take it on a logical outlook. Tim These quotations show that becoming a person who self-cannulates was viewed as a series of steps that occur over time to achieve a goal. The outcome of the process was that self-cannulation changed from "an ordeal. . . to the norm" (Rex). Linguistically, the term "process" changed in meaning as well when they had fully come to terms with selfcannulation: "It's just a process. It's just, to me, the same process as putting the lines on the machine" (Alf). Self-cannulation was no longer a series of steps but a procedure or routine in their dialysis treatment.

\section{Gaining control}

Gaining control was the first step in the process of becoming a self-cannulator. Six participants did not have a fear of needles prior to deciding to self-cannulate; however, two participants (Ike and Rex) stated they did have a fear or "a pathological dread of needles" (Rex). Gaining control occurred when they were psychologically ready to consider self-cannulation, "Well you know, you tend to get to a stage, a psychological stage to be able to needle yourself" (Ike). They described gaining control in three key ways: mentally, physically and lifestyle.

Mental control involved not allowing fear of needles to foster in one's mind, "When a needle goes in it's not the needle you're scared of it's the thought of the needle going in that scares you. It's the feelings we sort of make. It's your mind playing tricks on you" 
(Tim). Participants desired to take physical control of their own needling. They were often ready to take control after negative experiences with nurse-led cannulation or after becoming desensitized to self-cannulation (via self-injections with smaller needles, e.g., EPO or insulin):

It's surprisingly more painful [when nurses do your needles] because it's always a surprise. Alf

Actually, what first started [my self-cannulating] was I started having my injection on my own at home. . . started giving myself EPO once a week, then from there I was just like doing the needling, I'm not letting them blow my needle again, let's put it in. Ike

Thirdly, seeking control over their lifestyle was a potent motivation for self-cannulating. Participants saw self-cannulation as the key to a gateway that they wanted to access. Their desire for control of their lifestyle was greater than any fears or hesitations they had about self-cannulation.

How do you want to live your life - do you want to do this or do you want to do that? I mean the needles are irrelevant to that - it's your lifestyle. If that's the lifestyle you want, then you're going to do it. Eli

It's my quality of life I want while I'm here. Rex

Essential to having the lifestyle they wanted is being alive. Participants saw selfcannulation as enabling them to live:

If they [other patients] know that .... dialysis is what gives them a longer lifespan then they would learn to do it. It's like somebody in the... a soldier in the battlefront who has been shot, he has to tend his wounds doesn't he. Ike 
In this metaphor, Ike likened self-cannulation to a soldier (patient) in battle (dialysis) who must tends his wounds (self-cannulate) to live. This metaphor for self-cannulation epitomised the very stark association that these participants saw between selfcannulating and staying alive. Accepting self-cannulation as part of their life helped them to maintain their lifestyle whilst on dialysis and became recognised as the key to staying alive.

Participants also associated other lifestyle benefits with self-cannulation, ranging from freedom and independence, to benefits for their health (e.g., better clearance of the toxins in their blood and controlling the appearance of their fistula). Vic found numerous positive lifestyle and psychological benefits that self-cannulation afforded:

It's very good and you feel that you are independent, you don't need help from anyone else; you're not giving anyone any problems. I mean dialysis is something you have to do, you've just got to live with it, so you are doing it yourself and you're looking after your own health. So in that way you're sort of master of your own self destiny sort of thing, you're not depending on someone else, or you're not depending on the hospital or anything, you're doing it yourself. So I think that is a very good thing.

His views and attitude towards self-cannulation were echoed throughout all the participants' interviews. For these participants, gaining control either mentally, physically or of their lifestyle was the first step in the process of becoming a person who selfcannulates.

\section{Building confidence}

The next step in the process of a becoming a person who self-cannulates was building confidence: 
I think confidence is the big thing. . Ya know it takes a while. And that's it, you've got to persevere; you gotta have some mental toughness from that point of view because you've got to go through that process. Eli

Confidence was built and maintained through their training, experience, and support from others. The nursing team on the HHD training unit was often cited as giving them the confidence they needed:

I know I go on about the training unit but they're very good, and I can't imagine any other way of doing it. They give you the confidence anyway. It doesn't come from day one. Eli

I was fully conversant with everything that I would need [to self-cannulate]. The training really is excellent. Rex

They [training unit nurses] made me so confident. Leo However, the nursing team were not always essential in building confidence. Ike taught himself to self-cannulate after reading leaflets on cannulation provided in the dialysis waiting room. His confidence came from his own successful attempts at selfcannulating.

Participants also reported that experience helped them build their confidence with self-cannulation, "Experience, I think. There's not another way.... It is trial and error..." (Eli). For some of the participants, trial and success solidified their confidence and set them firmly within the process of becoming a self-cannulator:

First time it was a question of, 'Yep got to do this, right seen it, I know how to do it, know what I need to do'. Full of confidence, needle straight in. Alf I tried it once and it worked without a blow and that was it. Ike 
However, 'errors', or having incidents and mishaps, were seen as beneficial as it taught them how to handle situations in their own way. Tim used an analogy of driving a car to describe the learning curve of self-cannulating:

It's just like when I say, when you're driving, it's best to have an accident the first week and scrape your car and pay that fine, that penalty. And once you've gone past that you will learn very quickly not to do it. Tim Most discussed having had a few incidents at the training unit but stated that it was not until they were on their own at home that they learned exactly how to handle incidents and established the best routine for themselves. Rex stated that there could always be "hiccups" with self-cannulation but that they could be overcome. Many of the participants had or were experiencing 'hiccups' and relied on their confidence to get over their frustration, "Even now I do have the courage to do it, it's only when I can't get it in properly then you feel a bit frustrated" (Vic). At the time of the interview Vic was having issues with self-cannulation and described the complex role confidence played with selfcannulation - it requires confidence; it gives it; and it can take it from you:

Like I say it's very good for self-confidence. . . as long as I'm healthy, needling was no problem and everything was going well. . . It's just when your health goes down and needling becomes a problem that you find that the confidence goes down. . . it's been difficult every second or third time I can't do it . . so that's why you sort of lose confidence sometimes. Vic

As Vic highlighted, although confidence was built through training and experience, it also has to be maintained. Moral support from the community nurse team and their spouses was regarded as important in maintaining their confidence. Many stated that they were grateful to their community nurses for providing support: "I've 
never been keen on people looking over my shoulders, you know... but I was glad of somebody [the community nurse] being there at that time. It's just a bit of reassurance" (Rex). Eli too was glad to have moral support when he self-cannulated, "It's a great help to have somebody with you while you [self-cannulate], just to have a bit of moral support."

All of the participants did their own cannulation, but many of them spoke about the important role that their spouses played in assisting them (i.e., taping down their needles or helping remove a needle at the end of dialysis). Spouses were described as providing moral support when incidents happen:

When I prick [self-cannulate], she puts the tapes. . And the first one she puts and the other two [tapes] I put myself, but these are things she helps like this. . . She helps - whatever she can do she does. Leo

I'm lucky my wife is there so she helps me to get the fresh needles and set them there. Because now you are one needle here and you can't move yourself too much and you've got to get the other stuff in there. That's a bit of a stressful time. Vic

Becoming the norm

The third phase of the process of becoming someone who self-cannulates was that it became the norm for them. This stage included acceptance, normalisation and forming part of their identity. All the participants had come to terms with self-cannulation as something they have got to do and spoke about accepting it as part of their lives:

I just accepted it. It was just, if it's what you've got to do, you've got to do it. Alf It's just what I do. Hen 
Because l've accepted it now ... It's my way of life, it's how l'm going to live. . It's just part of life. Tim

The repetition of word 'just' in these quotations seems to downplay self-cannulation and suggests that they have normalised it. It is no longer an 'ordeal' and has now become 'just what I do' or the 'norm'. It was even stated as being "a good thing" (Vic) and "a minor thing" (Leo). They also likened self-cannulation to normal everyday tasks:

It's like picking up a knife and fork. It's second nature now. Hen Well, it's easy peasy now, it's like second to nothing, you know. Just put it in straight away, you know, and that's it. . I don't think about it, I just do it. Ike And now I don't think anything of it. Rex

Humour was also used when describing self-cannulation which seemed to act as a way of normalising it in their minds:

I think you become a bit more blasé about it. You think, 'Yes it's a needle, l'm putting straws in' [laughs]. Other people have needles, I have straws. Alf You could throw a dart at it [fistula] from 500 metres and still find a spot [cannulation site]. Hen

Despite self-cannulation becoming the norm, some participants revealed that they did still worry:

I've got a dread of a needle coming out or something. I do get a bit paranoid about these needles. Rex

Well, I sort of get in the mindset that I'm going to the 'office' [his dialysis room] I've got to do that today so that's what I do. Still slightly apprehensive that the needles won't work - slightly. But obviously it diminishes, but you're still glad when they go in and it works. Eli 
Vic mentioned that some days he needed to "perk himself up" to do it whereas Ike rationalized his fear of needles with his need to dialyse ("you could balance it psychologically that okay, I'm going to have to do this"). Although they were all proficient at self-cannulation and had fully accepted it as part of their life, problems with their needles or cannulating remained an underlying concern for them.

The concerns that they had about self-cannulation did not stop it from forming part of their identity. Being patients who self-cannulated set them apart from other patients and their peers. They found that they were treated differently, given more respect and spoken to differently, by health care professionals:

Because then, doctors treat you differently as well. They do treat you differently if you can use some of the words. They don't patronise; therefore, they reveal more information. And therefore you learn more. Hen

I find that with most people - [referring to his GP] he's quite, he thinks I'm quite brave to do it. Eli

When asked how they saw themselves and how others perceived them because they self-cannulate, they used words or phrases with positive connotations like "brave" (Leo), "courageous" (Vic), "confident" (Tim), "get a lot of kudos off my mates...just get a bit of respect" (Rex), "a soldier" (Ike), "strong-minded" (Hen), "survivor" (Eli), and "I'm doing something they don't think they could do" (Alf). However, participants did also describe having to deal with negative reactions to self-cannulating:

I've seen a few people go queasy when they see me putting the needle in, they say, 'Oh do you do that yourself, oh. . .', but I just say don't worry, I tell them the same thing the guy told me, when you start doing it yourself you won't let anyone do it. Ike 
Participants deal with these reactions by trying to educate people as to why selfcannulation is better for them (i.e., to manage the health and appearance of their fistula, to do longer dialysis sessions, to be independent). They expressed some disappointment that there is not a greater understanding in the public about ERF and dialysis in general. For these participants, despite negative reactions and even some underlying worries about their needles, self-cannulation had become the norm for them which included them accepting it, normalising it and forming a part of their identity.

The process of becoming a person who self-cannulates was described as having three main stages: gaining control, building (and maintaining) confidence, and becoming the norm. Although the process is represented as series of stages, it is a fluid and dynamic process that is responsive to the patients' wider context (e.g., their health, social situations).

\section{Discussion}

In this study we explored male HHD patients' experiences, views and perceptions of self-cannulation and aimed to highlight ways in which fears of self-cannulation could be overcome. The findings from this study provide an in-depth understanding of how a particular set of patients experienced and came to terms with self-cannulation. Even though the participants in this study were experts in their own care, they reflected on their experiences with self-cannulation and recognised that it could be a barrier, but one that could be overcome. Their interviews revealed how they began the process of becoming someone who self-cannulates which included them gaining control, building confidence and over time, self-cannulation becoming the norm. 
Similar to Glidewell et al. (2013), we found that patients can overcome their fears of self-cannulation, in our study, this was particularly so if they had previous experience of self-injecting. Patients who self-cannulate gain knowledge about dialysis and a number of skills which lead to them becoming increasingly proficient in their own care.

Gaining control was a critical step in the process of becoming someone who selfcannulates. As in our study, Glidewell et al. (2013) and Taylor et al. (2016) reported that some patients started self-cannulating because they felt they knew their fistula better than nurses. For many of these patients, taking control had the physical benefit of hurting less. Feeling in control is often cited in the literature as important to patients on dialysis or with other chronic illnesses as it is associated with positive effects such as promoting freedom and autonomy (Cases et al., 2011; Gregory, Way, Hutchinson, Barrett, \& Parfrey, 1998; Karamanidou, Weinman, \& Horne, 2014; Vestman et al., 2014).

Building self-confidence was important in becoming someone who selfcannulates. In Taylor et al. (2016), self-cannulation was also linked with building confidence and occurred when participants had successful experiences with cannulation. Moral support was also found to be critical to the maintenance of confidence. Taylor et al. (2016) noted the role spouses played in assisting with practical elements of self-cannulation (holding needles); spouses were reported by the participants in this study as providing similar assistance as well as providing integral moral support in some cases (Eli). The importance for educating and facilitating HHD of the team training those to self-cannulate has been cited as important (Glidewell et al., 2013; Wise et al., 2010). The participants in this study stated that this initial team of nurses were instrumental in giving them the confidence to take control and persevere with their training (n.b. six participants were trained to self-cannulate in a HHD 
preparation unit by nurses who are experienced in teaching patients to self-cannulate). Cases et al. (2011) patients also stated that HHD training time was important for building confidence and was maintained by the support patients received from their community dialysis nurses or primary caregivers (spouses). Other studies have highlighted the importance of strong, on-going informal and formal support in maintaining patients' confidence and adhering to treatment regimes in HHD (Namiki et al., 2010) and more generally in haemodialysis (Gregory et al., 1998), although these studies did not specifically discuss self-cannulation.

Studies exploring HHD patients' general experiences have reported themes complementary to those identified in this study (Cases et al., 2011; Curtin et al., 2002; Rygh et al., 2012; Wise et al., 2010). A key example is the qualitative semi-structured interview study conducted by Cases et al. (2011) which reported that patients embraced HHD because it gave them freedom and flexibility, that they re-established their identity and sense of self in relation to $\mathrm{HHD}$, and underwent steps to integrate aspects of the treatment into their lives. Within these themes, they discussed the time it took for patients to re-gain their confidence and to fully accept HHD as part of their lives. Their findings are highly congruent with how the participants in this study went through the process of becoming someone who self-cannulates. It was noted during analysis that participants sometimes found it hard to differentiate between self-cannulation specifically and HHD more generally (e.g., when participants were asked 'What are the benefits of self-cannulation?' many of the responses were related to HHD rather than directly related to self-cannulation). This fusion of self-cannulation and HHD highlights how fully integrated self-cannulation had become in the participants' routines and lives. 
This study is the first to our knowledge to discuss identity as a self-cannulator. The participants alluded to others when discussing how they viewed themselves.

Referring to others' perceptions when shaping personal meanings of identity indicates a symbolic interactional process of identity formation in relation to illness (Lively \& Smith, 2011). The participants used phrases and words with positive connotations such as 'survivor' and 'brave', also utilised in other illnesses such as cancer, that may impact personal and social meanings and responses to illnesses or treatments (Lively \& Smith, 2011). Their identity in relation to self-cannulation may have promoted their access to additional interpersonal resources (Callero, 1994), such as gaining 'kudos' from friends and respect from their health care professionals. For these participants self-cannulation performed a positive function in their emerging illness related identity.

The theme of normalising dialysis and the dialysis routine has been reported in Similar to findings from other qualitative studies with dialysis and HHD patients (Courts, 2000; Lee et al., 2008; Rygh et al., 2012), the process of becoming someone who selfcannulates culminated with the patients normalising it as part of their HHD routine and ultimately part of their lives. Previous studies reported that individuals developed coping strategies which allowed them to play down $f$ having a chronic illness and thus helped them to live as normally as possible. They also discussed lingering apprehensions and anxieties that they about the fistula or cannulation technique, similar to findings of Jayanti et al. (2015) where HHD patients reported their greatest concern was related to procedural complications.

A strength of this study was the usage of qualitative interviews to explore male HHD patients' experiences of self-cannulation. Furthermore, we were able to recruit an ethnically diverse sample of men living in the UK. Within the sample, neither age nor 
their cultural background acted as a barrier to self-cannulation, although older age and minority groups have been linked with unsuccessful adherence on HHD (Komenda, Copland, Er, Djurdjev, \& Levin, 2008). Although previous researchers have employed qualitative interviews in which self-cannulation was discussed (Cafazzo et al., 2010), the present study focused on self-cannulation and sought to explore the underlying beliefs and perceptions held about it by the participants. In contrast to the literature, selfcannulation was not the focus of the participants' attention when deciding which modality to choose. They stated that they chose HHD and to self-cannulate based on the benefits which it afforded them, namely lifestyle, quality of life and health factors. Self-cannulation has been reported in the literature as a barrier to HHD uptake (Cafazzo et al., 2010; Morton et al., 2011; Morton et al., 2010; Pipkin et al., 2010; Tennankore et al., 2012; Walker et al., 2015); however this study's findings suggest it could be overcome by first understanding patients' goals and highlighting how self-cannulation and HHD could benefit the patient and facilitate the achievement of those goals.

An all male sample was selected for this study to provide a homogenous sample within which to explore the key area of research, self-cannulation. The analysis yielded the temporal meanings that self-cannulation took on for these participants and recognises the profound meanings they assign to self-cannulation, and ultimately themselves. Due to the exploratory nature of the study, we did not set the findings within a theoretical framework but have linked it to existing psychological theory where applicable. Further to this, we have presented an interpretative level of analysis where the data warranted it (Smith et al., 2009) and used a descriptive analysis in other areas to avoid speculation (Willig, 2008). For example, the theme "male identity related to selfcannulation" was explored; however, participants did not explicitly link self-cannulation 
with being a male or male identity. In future work the views of female HHD patients should be examined for consistency and deviations from this study as they would offer unique contributions to this area of enquiry.

In our study, the perspectives obtained were from patients with overall successful experiences with self-cannulation. As is standard practice throughout the UK, most patients had received training in self-cannulation prior to starting HHD. Although the majority were trained at one HHD training unit (six participants), one was trained at another renal unit and one was self-taught while at another unit. The perspectives from those who have had difficulty with self-cannulation after training or have stopped selfcannulating could also offer valuable insight, and it might also be of interest to relate self-cannulation success or failure to differences between training programmes.

Researchers play a critical role in data generation and interpretation (Pope \& Mays, 2006); therefore, it is important to acknowledge possible influences that the team could have had on the study. The first author was new to this field of research at the time of the study so approached it with relatively few preconceptions. She bracketed her emerging thoughts about the topic throughout the research process by keeping a reflexivity journal during the data collection and during the analysis and interpretation phases. These were reviewed with the research team through regular meetings. Participants were made aware that the researcher was not affiliated with the participants' hospital or renal care team, and appeared eager to discuss their experiences of HHD and self-cannulation. This led to lengthy interviews which addressed topics which were outside the remit of the present study. Though these details enlightened the researcher to the participants' background and experiences, they may have led the researcher to rely on implicit meanings. During analysis, the 
researcher referred to her notes, the full transcript, or the audio-recording for clarity of meaning to avoid misinterpretation.

\section{Clinical implications}

The findings from this study may inform health care professionals' approach to facilitating the uptake of self-cannulation, and ultimately shared-care or HHD. In particular, some participants in this study directly attributed their desire to learn and overcome mental barriers to self-cannulation based on their successful experiences of injecting their own insulin and EPO. This step may have desensitized them to needles and developed self-efficacy for self-care (Bag \& Mollaoglu, 2010; Lev \& Owen, 1998). Our findings also highlighted that even experienced, expert patients require on-going moral support over the course of their treatment. Providing opportunities to re-train in techniques or acquire more extensive information about their treatment (e.g., the fistula or mechanics of dialysis) may also facilitate adherence. Further to this, renal teams who offer respite services to patients' families, who often provide instrumental or moral support during self-cannulation, may increase HHD's long-term feasibility for this patient group.

\section{Conclusion}

Self-cannulation is perceived by some patients as a key to a number of benefits. The barrier of self-cannulation can be overcome by focusing on patients' lifestyle and health aspirations. This study also provided insight into the challenges and benefits of self-cannulation from the point of view of patients established on HHD. They described a process by which self-cannulation became part of their identity. This process was characterised by gaining control, building confidence and self-cannulation becoming the norm. Recognising the role that psychological and social factors have in initiating and 
maintaining self-cannulation may assist health care professionals and patients alike.

These findings address basic psychological and social needs, such as confidence and moral support, which may be relevant to patients in other countries with similar development and health services.

\section{Conflict of Interest Statement}

All authors declare no conflict of interest. 


\section{References}

Bag, E., \& Mollaoglu, M. (2010). The evaluation of self-care and self-efficacy in patients undergoing hemodialysis. J Eval Clin Pract, 16(3), 605-610. doi: 10.1111/j.13652753.2009.01214.x

Brocki, J. M., \& Wearden, A. J. (2006). A critical evaluation of the use of interpretative phenomenological analysis (IPA) in health psychology. Psychology \& Health, 21(1), 87-108. doi: 10.1080/14768320500230185

Cafazzo, J. A., Leonard, K., Easty, A. C., Rossos, P. G., \& Chan, C. T. (2010). Patient perceptions of remote monitoring for nocturnal home hemodialysis. Hemodialysis International, 14(4), 471-477. doi: 10.1111/j.1542-4758.2010.00473.x

Callero, Peter L. (1994). From Role-Playing to Role-Using: Understanding Role as Resource. Social Psychology Quarterly, 57(3), 228-243. doi: 10.2307/2786878

Cases, Alejandra, Dempster, Martin, Davies, Mark, \& Gamble, Gary. (2011). The experience of individuals with renal failure participating in home haemodialysis: An interpretative phenomenological analysis. Journal of Health Psychology, 16(6), 884-894. doi: 10.1177/1359105310393541

Courts, N. F. (2000). Psychosocial adjustment of patients on home hemodialysis and their dialysis partners. Clinical Nursing Research, 9(2), 177-190. doi: DOI: $10.1177 / 105477380000900206$

Curtin, R. B., Mapes, D., Petillo, M., \& Oberley, E. (2002). Long-term dialysis survivors: A transformational experience. Qualitative Health Research, 12(5), 609-624. doi: $10.1177 / 104973202129120133$

Glidewell, L., Boocock, S., Pine, K., Campbell, R., Hackett, J., Gill, S., . . Yorkshire Humber, Shared. (2013). Using behavioural theories to optimise shared 
haemodialysis care: a qualitative intervention development study of patient and professional experience. Implementation Science, 8. doi: 10.1186/1748-5908-8118

Gregory, D. M., Way, C. Y., Hutchinson, T. A., Barrett, B. J., \& Parfrey, P. S. (1998). Patients' perceptions of their experiences with ESRD and hemodialysis treatment. Qualitative Health Research, 8(6), 764-783. doi: 10.1177/104973239800800604 Jayanti, A., Foden, P., Wearden, A., Morris, J., Brenchley, P., Mitra, S., \& Grp, BasicHhd Study. (2015). Self-Cannulation for Haemodialysis: Patient Attributes, Clinical Correlates and Self-Cannulation Predilection Models. Plos One, 10(5). doi: 10.1371 /journal.pone. 0125606

Karamanidou, Christina, Weinman, John, \& Horne, Rob. (2014). A qualitative study of treatment burden among haemodialysis recipients. Journal of Health Psychology, 19(4), 556-569. doi: 10.1177/1359105313475898

Komenda, P., Copland, M., Er, L., Djurdjev, O., \& Levin, A. (2008). Outcomes of a provincial home haemodialysis programme--a two-year experience: establishing benchmarks for programme evaluation. Nephrology Dialysis Transplantation, 23(8), 2647-2652. doi: doi: 10.1093/ndt/gfn065

Lee, Anne, Gudex, Claire, Povlsen, Johan V., Bonnevie, Birgitte, \& Nielsen, Camilla P. (2008). Patients' views regarding choice of dialysis modality. Nephrology Dialysis Transplantation, 23(12), 3953-3959. doi: 10.1093/ndt/gfn365

Lev, E. L., \& Owen, S. V. (1998). A prospective study of adjustment to hemodialysis. ANNA J, 25(5), 495-504; discussion 505-496.

Lively, Kathryn J., \& Smith, Carrie L. (2011). Identity and IIIness. In B. A. Pescosolido, J. K. Martin, J. D. McLeod \& A. Rogers (Eds.), Handbook of the Sociology of Health, 
IIIness, and Healing: A Blueprint for the 21st Century (pp. 505-525). New York, NY: Springer New York.

MacNeill, S J, Casula, A, Shaw, C, \& Castledine, C. (2016). UK renal registry 18th annual report: Chapter 2 UK renal replacement therapy prevalence in 2014: National and centre-specific analyses. Nephron, 132(Suppl 1), 41-68. doi: $10.1159 / 000444816$

Majeed-Ariss, R., Jayanti, A., Schulz, T., Wearden, A., \& Mitra, S. (2016). The anticipated and the lived experience of home and in-centre haemodialysis: Is there a disconnect? J Health Psychol. doi: 10.1177/1359105316630135 Mitra, Sandip, \& Jayanti, Anuradha. (2014). Clinical outcomes and quality of life for home haemodialysis patients. Journal of Renal Nursing, 6(5), 220-225. doi: 10.12968/jorn.2014.6.5.220

Morton, R. L., Tong, A, Webster, A C., Snelling, P, \& Howard, K. (2011). Characteristics of dialysis important to patients and family caregivers: a mixed methods approach. Nephrology Dialysis Transplantation, 26(12), 4038-4046. doi: 10.1093/ndt/gfr177

Morton, R. L., Tong, A., Howard, K., Snelling, P., \& Webster, A. C. (2010). The views of patients and carers in treatment decision making for chronic kidney disease: systematic review and thematic synthesis of qualitative studies. British Medical Journal, 340, 10. doi: 10.1136/bmj.c112

Mowatt, G., Vale, L., \& MacLeod, A. (2004). Systematic review of the effectiveness of home versus hospital or satellite unit hemodialysis for people with end-stage renal failure. International Journal of Technology Assessment in Health Care, 20(3), 258-268. 
Namiki, Satoko, Rowe, Jennifer, \& Cooke, Marie. (2010). Living with home-based haemodialysis: insights from older people. Journal of Clinical Nursing, 19(3-4), 547-555. doi: 10.1111/j.1365-2702.2009.02901.x

National Kidney Foundation. (2002). KDOQI clinical practice guidelines for chronic kidney disease: evaluation, classification, and stratification. American Journal of Kidney Diseases, 39(Suppl 1), S1-S266.

Pipkin, M., Eggers, P. W., Larive, B., Rocco, M. V., Stokes, J. B., Suri, R. S., \& Lockridge, R. S. (2010). Recruitment and Training for Home Hemodialysis: Experience and Lessons from the Nocturnal Dialysis Trial. Clinical Journal of the American Society of Nephrology, 5(9), 1614-1620. doi: 10.2215/cjn.02440310

Pope, C., \& Mays, N. (2006). Quality in qualitative health research. In C. Pope \& N. Mays (Eds.), Qualitative research in health care (3rd ed., pp. 82-101). Oxford, UK: Blackwell Publishing, Ltd.

Rygh, Ellen, Arild, Eli, Johnsen, Elin, \& Rumpsfeld, Markus. (2012). Choosing to live with home dialysis-patients' experiences and potential for telemedicine support: a qualitative study. Bmc Nephrology, 13. doi: 10.1186/1471-2369-13-13

Smith, J. A., Flowers, P., \& Larkin, M. (2009). Interpretative phenomenological analysis: Theory, method and research. London, UK: SAGE Publications Ltd.

Tennankore, K. K., Chan, C. T., \& Curran, S. P. (2012). Intensive home haemodialysis: benefits and barriers. Nature Reviews Nephrology, 8(9), 515-522. doi: 10.1038/nrneph.2012.145

Tong, A., Sainsbury, P., \& Craig, J. (2007). Consolidated criteria for reporting qualitative research (COREQ): a 32-item checklist for interviews and focus groups. 
International Journal for Quality in Health Care, 19(6), 349-357. doi:

10.1093/intqhc/mzm042

Vestman, C., Hasselroth, M., \& Berglund, M. (2014). Freedom and confinement:

patients' experiences of life with home haemodialysis. Nursing research and practice, 2014, 252643-252643. doi: 10.1155/2014/252643

Walker, Rachael C., Hanson, Camilla S., Palmer, Suetonia C., Howard, Kirsten, Morton, Rachael L., Marshall, Mark R., \& Tong, Allison. (2015). Patient and Caregiver Perspectives on Home Hemodialysis: A Systematic Review. American Journal of Kidney Diseases, 65(3), 451-463. doi: 10.1053/j.ajkd.2014.10.020

Wilkie, Martin. (2011). Home dialysis-an international perspective. NDT Plus, 4(suppl_3), iii4-iii6. doi: 10.1093/ndtplus/sfr129

Willig, Carla. (2008). Phenomenological methods Introducing qualitative research in psychology: adventures in theory and method (pp. 52-73): Open University Press.

Wise, M., Schatell, D., Klicko, K., Burdan, A., \& Showers, M. (2010). Successful daily home hemodialysis patient-care partner dyads: Benefits outweigh burdens. Hemodialysis International, 14(3), 278-288. doi: 10.1111/j.15424758.2010.00443.x

Wong, Jennifer, Eakin, Joan, Migram, Paul, Cafazzo, Joseph A., Halifax, Nancy V. D., \& Chan, Christopher T. (2009). Patients' experiences with learning a complex medical device for the self-administration of nocturnal home hemodialysis. Nephrology Nursing Journal, 36(1), 27-32. 


\section{Tables}

Table 1

Topic guide: Self-cannulation questions and prompts

- How do you feel about doing your needles on your own? (How has doing your own needles changed from the early days to now?)

- What role did doing your own needles play in your decision to do home haemodialysis? (What experiences did you have of needling before learning to do your own dialysis needles?)

- Patients express different views and experiences of self-cannulation. Can you tell me how you have found it? (How has doing your own needles affected your view of having injections/blood taken?)

- How did you find your training for needling? (How did you find the information you got on needling from nurses/doctors/other patients?)

- What do you think are the good/bad things about doing your own needles?

- How you think people see you because you do your own needles?

- How do you see yourself for doing your own needles?

- What type of person do you think you need to be to do your own needles? 
Table 2

Participant demographic and background information

\begin{tabular}{ccccc}
\hline Participant & $\begin{array}{c}\text { Age } \\
\text { Range }\end{array}$ & Ethnicity & Prior experience with needles & $\begin{array}{c}\text { Duration of HHD } \\
\text { (months })\end{array}$ \\
Alf & $50-59$ & British European & Self-injections & 13 \\
Eli & $70-79$ & British European & Self-injections & 17 \\
Hen & $50-59$ & British European & Self-cannulated in HospHD & 34 \\
Ike & $40-49$ & African & Self-injections and self-cannulated & 32 \\
in HospHD & 50 \\
Rex & $50-59$ & Middle Eastern & Self-injections & 12 \\
Tim & $40-69$ & British European & Asian & Self-injections \\
Vic & $50-59$ & Middle Eastern & Self-injections & 14 \\
\hline
\end{tabular}

Note. $\mathrm{HHD}=$ home haemodialysis; HospHD = hospital haemodialysis. 
Table 3

Thematic model of the data

Central theme

Becoming a person who self-cannulates is a process

\begin{tabular}{|c|c|c|}
\hline Super-ordinate themes & Sub-themes & Description \\
\hline \multirow[t]{3}{*}{ Gaining control } & Mentally & $\begin{array}{l}\text { Not allowing mental fears to build } \\
\text { in relation to self-cannulation. }\end{array}$ \\
\hline & Physically & $\begin{array}{l}\text { Taking control of the act of self- } \\
\text { cannulating. }\end{array}$ \\
\hline & Lifestyle & $\begin{array}{l}\text { Realising it kept them alive and } \\
\text { allowed them the lifestyle and } \\
\text { benefits they wanted. }\end{array}$ \\
\hline \multirow[t]{3}{*}{ Building confidence } & Training & $\begin{array}{l}\text { Good training and positive } \\
\text { support from nurses. }\end{array}$ \\
\hline & Experience & $\begin{array}{l}\text { Learning through "trial and error" } \\
\text { and successes. }\end{array}$ \\
\hline & Support from others & $\begin{array}{l}\text { Having moral support when } \\
\text { mistakes happen during self- } \\
\text { cannulation }\end{array}$ \\
\hline \multirow[t]{3}{*}{ Becoming the norm } & Accepting & $\begin{array}{l}\text { Seeing self-cannulation as an } \\
\text { integral part of what they do and } \\
\text { their treatment. }\end{array}$ \\
\hline & Normalising & $\begin{array}{l}\text { Comparing it to daily routines } \\
\text { and using humour. }\end{array}$ \\
\hline & $\begin{array}{l}\text { Forming part of their } \\
\text { identity }\end{array}$ & $\begin{array}{l}\text { Being different from other } \\
\text { patients and associating it with } \\
\text { positive characteristics. }\end{array}$ \\
\hline
\end{tabular}

